\title{
TERRITÓRIOS EXISTENCIAIS DA FORMAÇÃO DOCENTE: EXPECTATIVAS E COMPREENSÕES DOS ESTUDANTES SOBRE O CURSO DE LICENCIATURA EM EDUCAÇÃO DO CAMPO
}

\section{EXPECTATIONS AND UNDERSTANDINGS OF THE STUDENTS ABOUT THE COUNTRYSIDE EDUCATION DEGREE: EXISTENTIAL TERRITORIES OF TEACHER TRAINING}

\author{
Raquel Silveira da Silva* \\ Luiz Fernando Mackedanz ${ }^{*}$
}

\begin{abstract}
RESUMO: Neste artigo, trabalhamos com a perspectiva cartográfica dos territórios existenciais da formação docente, identificados a partir do curso de Licenciatura em Educação do Campo da Universidade Federal do Rio Grande (FURG), cujo objetivo é formar professores e gestores habilitados para atuar nos anos finais do Ensino Fundamental através de uma proposta pedagógica direcionada para a valorização da Educação do Campo. Aqui, apresentamos as expectativas e compreensões dos estudantes, obtidas através de uma análise cartográfica das entrevistas realizadas. A partir do dialogismo entre as falas dos sujeitos e o referencial teórico, identificamos a delimitação dos territórios existenciais habitados pelos discentes do curso. Verificamos o entendimento destes estudantes sobre a importância da formação de professores para o nível básico de forma exclusiva e direcionada para a atuação junto à Educação do Campo, dialogando com os autores específicos destas áreas. Finalmente, trazemos algumas considerações e possibilidades de uma abordagem de formação docente articulada às vivências dos discentes, que visam colaborar no quadro atual referente à formação de professores para a educação do campo.
\end{abstract}

Palavras-chave: Pedagogia da Alternância; Contextualização; Cartografia.

ABSTRACT: In this article, we work with a cartographic perspective of existential territories in teacher training, identified from the Teacher Training for Country Education Degree at the Federal University of Rio Grande - FURG, whose aims are to train teachers and managers qualified to work in basic education in the final years of Elementary School through a pedagogical proposal that meets the perspectives of educational scope, aimed at enhancing the education of the field through access to the university. Next, we present the expectations and understandings of the students, obtained through a cartographic analysis for the accomplished interviews. From the

\footnotetext{
"Mestrado em Educação em Ciências pela Universidade Federal do Rio Grande (FURG). Integrante dos grupos de pesquisa "Educação a Distância e Tecnologia" (EaD-TEC) e "Ecologia cognitiva digital: compartilhamento e cooperação em ambientes digitais". Contato: raquelsds2013@gmail.com

** Doutorado em Física pela Universidade Federal do Rio Grande do Sul (UFRGS). Docente da Universidade Federal do Rio Grande (FURG), atuando junto ao Programa de Pós-Graduação em Educação em Ciências (PPGEC) e no mestrado profissional em Ensino de Física (MNPEF).Contato: luismackedanz@furg.br
} 
dialogism between the subjects' speeches and our theoretical references, we identify the delimitation of the existential territories inhabited by the students of the course. We verified the understanding of these students about the importance of teacher training for Basic Level in an exclusive way, directed to the action at Field Education, dialoguing with the specific authors of both áreas. Finally, we bring some considerations and possibilities of an approach of teacher formation articulated the experiences of the students, who aim to collaborate in the current framework regarding the training of teachers for the education of the field.

Keywords: Alternation Pedagogy; Contextualization; Cartography.

\section{INTRODUÇÃO}

Em 2012, foi lançado o Programa Nacional de Educação do Campo PRONACAMPO, cujo propósito seria assegurar à população da zona rural qualidade e dignidade essenciais para a vida no campo. O Ministério da Educação, por intermédio da Secretaria de Educação Superior - SESU, Secretaria de Educação Profissional e Tecnológica - SETEC e da Secretaria de Educação Continuada, Alfabetização, Diversidade e Inclusão - SECADI, publicou o Edital SESU/SETEC/SECADI/MEC n. 2 em 5 de setembro de 2012. Tal edital, no âmbito do Programa de Apoio à Formação Superior em Licenciatura em Educação do Campo - PROCAMPO - convocava as Instituições Federais de Educação Superior a apresentarem Projetos Pedagógicos para cursos presenciais de Licenciatura em Educação do Campo.

Nesse contexto, a Universidade Federal do Rio Grande (FURG) oferta o curso com Ênfase em Ciências da Natureza e Ciências Agrárias, no campus de São Lourenço do Sul, cidade localizada a cerca de $100 \mathrm{~km}$ do campus sede, escolhida por sua importância na agricultura familiar e na cultura quilombola e indígena - o público-alvo do curso, de acordo como o edital. Seu objetivo é a formação de educadores para atuação na Educação Básica, especificamente atendendo Anos Finais do Ensino Fundamental e Ensino Médio em escolas do Campo.

O curso foi planejado com o propósito de atender às necessidades das comunidades local e vizinhas à cidade de São Lourenço do Sul, que possuíam pouco acesso ao Ensino Básico e Superior. Esse quadro, em especial referente ao acesso à Educação Básica do campo, passa por mudanças, contribuindo 
para que novos alunos e professores em formação para atuar neste contexto alcancem ao Ensino Superior. Além disso, o processo deve levar a uma Educação Básica que valorize as necessidades dos povos que vivem no campo, isto é, que contemple os saberes experienciais e sociais de cada sujeito do campo e não apenas os saberes científicos.

Acreditamos que não basta apenas garantir esse acesso, mas oportunizar uma formação docente para atuar neste contexto, pois ainda verificamos a presença do professor especialista disciplinar nas Escolas do Campo, que utiliza as mesmas práticas pedagógicas desenvolvidas com os alunos da cidade; entendemos, porém, que o professor que atua no campo precisa inserir na sua prática docente o contexto no qual os estudantes estão inseridos. Dessa forma, as políticas públicas já estão planejando a formação do professor que irá atuar no campo a partir de uma formação inicial voltada para esse ambiente.

Convidamos o leitor, neste artigo, a investigar as expectativas e compreensões dos acadêmicos do curso com relação às práticas cotidianas e aos conhecimentos científicos trabalhados no espaço da Universidade, bem como refletir sobre as políticas públicas vigentes para o ensino de ciências no contexto do Campo, o papel do professor frente aos novos modelos de ensino para uma melhor atuação no campo e a importância de se pensar e produzir práticas pedagógicas contextualizadas ao campo. A partir dessas compreensões, delimitamos os territórios existenciais dos discentes participantes da pesquisa, bem como criamos o nosso próprio. $E$, dos compartilhamentos entre esses diferentes territórios, trazemos elementos para verificar as práticas pedagógicas percebidas pelos entrevistados.

O presente estudo surge dessas inquietações e questionamentos, que permeiam o ensinar no contexto do campo, prevendo novas práticas pedagógicas articuladas aos conhecimentos científicos e é resultante das análises da pesquisa de mestrado. O foco deste artigo está na identificação das diferentes percepções discentes sobre o curso de Licenciatura em Educação do Campo (a partir daqui referido pelo acrônimo CLEC).

A proposição da Educação do Campo abre um espaço para repensarmos algumas práticas pedagógicas e sociais, possibilitando que 
escola e demais instituições de ensino desenvolvam um trabalho articulado às diferentes áreas do conhecimento, em parceria com a comunidade local. Por esse motivo, o design do CLEC já busca a formação de uma equipe de docentes com habilidades e experiências nesta área, buscando atender às perspectivas de âmbito educacional voltadas para a valorização da educação do campo, a partir de propostas pedagógicas e saberes voltados para essa realidade.

$\mathrm{Na}$ próxima seção, apresentamos nosso referencial metodológico, discorrendo sobre o significado do território existencial e apresentando alguns conceitos utilizados sob a ótica das pistas cartográficas. Para caracterizar 0 território, apresentamos o CLEC como nosso espaço a ser habitado. Após, apresentamos a análise das entrevistas desenvolvidas com os discentes do curso, realizando um diálogo com o referencial teórico, que não é explicitado inicialmente, para compor o movimento de ida e volta comum às análises via pistas cartográficas. Encerramos com um resumo dos achados neste trabalho, bem como a sinalização de pontos que podem ser considerados no panorama atual da educação do campo.

\section{REFERENCIAL METODOLÓGICO E TERRITÓRIOS EXISTENCIAIS}

Entende-se por território existencial não apenas o estado físico, como o ambiente do curso, mas o estado emocional de cada sujeito que participa dele, inclusive dos pesquisadores implicados, o que já caracteriza o trabalho como pesquisa participante (BOGDAN; BIKLEN, 1994). O território existencial deve estar permeado por expressões, emoções e vivências dos sujeitos que se relacionam, pois "é sempre pelo compartilhamento de um território existencial que sujeito e objeto da pesquisa se relacionam e se codeterminam" (ALVAREZ; PASSOS, 2012, p.131). Por si só, cada sujeito participante da pesquisa pode ser analisado em seu território existencial. Aqui, entendemos que existem diferentes territórios existenciais onde os sujeitos compartilham experiências de vida e, conforme vivenciam diferentes territórios, vão se transformando, amadurecendo e aprendendo com os novos territórios habitados. E são esses territórios existenciais de cada sujeito imbricado no processo que são 
analisados ao longo de nossos passos cartográficos (KASTRUP et al., 2012), de forma a constituir o próprio território do CLEC.

No entanto, nem sempre sabemos e conhecemos este território, muitas vezes nos sentimos perdidos, à deriva (no sentido de andar sem rumo). Esta caminhada, muitas vezes, traz desassossego ao pesquisador, pela falta de observação aos fenômenos que ocorrem ao seu redor; como cartógrafo, esta atenção permite focar no que realmente toca e impulsiona a descrever o território, o que gera um aprendizado que deve ser cultivado (KASTRUP et al, 2012). Além disso, habitar num território existencial exige acompanhamento de processos ao longo da pesquisa, pois esses espaços transformam-se, ou seja, as ações e emoções que tocavam e impulsionavam para ao estudo de determinado fenômeno passam a ser analisadas pelo pesquisador com outro olhar. Estamos falando da desterritorialização de um território já habitado, isto é, mudanças de atitudes, concepções e crenças que nos constituem enquanto sujeitos.

Neste cenário, precisamos aprender a lidar com essas mudanças, pois fazem parte dos diferentes caminhos percorridos e que podem contribuir, tanto positivamente como negativamente, para a nossa formação; isso depende apenas da forma como habitamos os diferentes territórios existenciais, isto é, depende das nossas ações/emoções/atitudes. Assim, buscamos "habitar um território existencial singular" (ALVAREZ; PASSOS, 2012, p. 131), ou seja, acompanhar a construção dele a partir das relações percebidas pelos discentes do CLEC entre as áreas do conhecimento e suas práticas cotidianas.

Para isso, nos servimos de Kastrup et al. (2012), que fornece pistas para a utilização do método cartográfico de pesquisa, a partir do acompanhamento e análise dos sujeitos, através de suas vivências, culturas, contextos, histórias de determinação e superação, dos modelos de ensino ainda predominante no espaço universitário e das inúmeras dificuldades por parte dos que decidiram se inserir no território em estudo, neste caso, o CLEC. Nossa análise acontece na processualidade dos fatos que nos tocam, mas "existem dois sentidos para a palavra processualidade e que tanto pode remeter à noção de processamento quanto a de processualidade" (BARROS e KASTRUP, 2012, p. 58). Para os autores, o sentido de processamento está relacionado somente à 
coleta de dados e à análise de informações. Já a ideia de processualidade está presente em cada momento da pesquisa, nos avanços e paradas que nos tocam, ao longo do estudo. Por esse motivo, focaremos neste último sentido, por entendermos que a cartografia acontece ao longo de diferentes processos que nos fazem questionar nossas ações e compreensões.

Nesse sentido, a cartografia, como metodologia de pesquisa (DELEUZE; GUATTARI, 1995), caracteriza-se por entender que cada informação, cada ação sobre um tema faz parte de um processo e esse, por sua vez, se dá ao longo de um caminho entendido por muitos como o "dar-se conta" sobre teorias, intenções e diversos temas que estão presentes no trabalho. Falar e/ou escrever de forma cartográfica nada mais é do que estar inserido nessa linguagem, que vai sendo compreendida pelo leitor/pesquisador ao se apropriar das contribuições teóricas sobre o tema, o que torna a escrita e a análise da construção do território existencial cada vez mais ricas em linguagem com rigor científico.

Aqui nos referimos ao processo de imersão nos conceitos presentes nesta pesquisa, pois "a pesquisa de campo requer a habitação de um território que em princípio, ele não habitava" (KASTRUP et al., 2012, p. 56). Neste trabalho, o ethos (morada e estilo) está nas relações entre as Ciências da Natureza e Ciências Agrárias articuladas às práticas cotidianas percebidas pelos discentes do Curso. Entretanto, sabemos que "numa pesquisa não podemos iniciar com um problema fechado, sabendo de antemão o que se busca" (ALVAREZ; PASSOS, 2012, p.138), por esse motivo estamos atentos aos diferentes caminhos possíveis que a pesquisa nos direcionará.

A Universidade Federal do Rio Grande (FURG) imbuída do seu compromisso com o desenvolvimento humano e social do cordão litorâneo sulrio-grandense propôs a criação do Curso de Licenciatura em Educação do Campo, com ênfase em Ciências da Natureza e Ciências Agrárias, no Campus de São Lourenço do Sul, com a pretensão de fortalecer as escolas do campo, indígenas e quilombolas, por meio das tradições de pequenos agricultores, voltados para a agricultura familiar. De acordo com o Projeto Pedagógico, o curso objetiva atender às necessidades da população do campo dando acesso à formação inicial em nível superior a fim de formar professores e gestores 
habilitados a atuar na educação básica no campo, uma vez que a Lei de Diretrizes e Bases (BRASIL, 1996) enfatiza, em seu Art. 28, a necessidade de uma adaptação especial aos conteúdos próprios do cotidiano dos povos do campo:

\begin{abstract}
Art. 28 - Na oferta de educação básica para população rural, os sistemas de ensino promoverão as adaptações necessárias a sua adequação às peculiaridades da vida rural e de cada região, especialmente: I - conteúdos curriculares e metodologias apropriadas às peculiaridades da vida rural e de cada região; II - organização escolar própria, incluindo adequação do calendário escolar e as fases do ciclo agrícola e às condições climáticas; III - adequação à natureza do trabalho na zona rural (BRASIL, 1996).
\end{abstract}

No ano de 1998 acontece a 1a Conferência Por uma Educação do Campo (ARROYO; FERNANDES, 1999), organizada pelo MST, contando com o apoio de vários parceiros, entre eles o órgão da Organização das Nações Unidas para a Educação, Ciência e Cultura - UNESCO. Essa conferência, de âmbito nacional, foi considerada como marco da ruptura entre pensar em uma educação rural e uma educação do e no campo que tem como protagonistas os sujeitos coletivos, isto é, todos aqueles que se unem pela causa do campo e por uma educação que contemple a realidade dos sujeitos. Utilizaremos neste estudo o termo educação do campo e não simplesmente educação rural, pois nosso interesse está em acompanhar os sujeitos que atuam no CLEC.

Nesta mesma conferência, optou-se pela ideia de Educação do Campo, pois entende-se que “com esta expressão 'campo', há uma abrangência maior de sociedades diversas que habitam as regiões do país que não se dizem urbanas." (ROSA; CAETANO, 2008, p. 23). Assim, a diferença entre os termos é necessária, uma vez que o modelo educacional então vigente apontava para uma interpretação onde "a educação rural era predominantemente vista como algo que atendia a uma classe da população que vivia num atraso tecnológico, subordinado, a serviço da população dos centros urbanos" (ROSA; CAETANO, 2008, p. 23). Assim, a implantação da ideia de Educação do Campo permite inclusão e valorização das pessoas que habitam o meio rural, através da partilha e socialização de suas experiências, de forma igualitária, de forma a estabelecer uma relação harmoniosa e democrática entre as relações humanas e as de produção. 
Este cenário de luta por novos territórios que valorizem a ação dos sujeitos que vivem e dependem do campo motiva educadores, pesquisadores e demais sujeitos envolvidos no campo a criarem o CLEC, no qual buscam contextualizar e ressignificar os saberes do campo no ensino superior, mantendo assim a cidadania, cultura e tradições locais, o que oportuniza a permanência dos filhos dos pequenos produtores/agricultores nas suas cidades de origem através de uma formação profissional para o campo (FURG, 2013).

Para uma melhor discussão sobre o projeto pedagógico do CLEC, definimos aqui a disciplina como o elemento curricular definido por uma única área, normalmente referido como "conhecimento fragmentado" (JAPIASSU, 1976). É importante apontar aqui, porém, que essa definição de disciplina deve ser suavizada, visto que a evolução dos conceitos científicos ocorre pela pesquisa, e esta deve ser realizada em áreas específicas (JANTSCH; BIANCHETTI, 2011). Voltando ao CLEC, a concepção sobre o caráter multidisciplinar vem pelo estímulo à flexibilidade das fronteiras entre as disciplinas, visto que a formação do licenciando envolve saberes disciplinares diversos, bem como a necessidade de integração desses saberes. Isso ocorre porque o currículo está estruturado em unidades de caráter modular, cartesianas, mas propõe uma imersão em atividades integradas (traduzidas no PPC como multidisciplinares) por meio de atividades e projetos com diferentes áreas do conhecimento e em atividades interdisciplinares as quais as disciplinas conversam entre si e se articulam contribuindo para que novos conhecimentos possam emergir através das práticas interdisciplinares.

Nesse contexto, o projeto pedagógico também estabelece eixos orientadores, a saber: contextualização da educação do campo, formação do professor, estudos específicos e articulação social e comunitária, os quais estão estruturados em regime de alternância. O primeiro eixo tem por objetivo a valorização da identidade docente, o segundo eixo contempla disciplinas comuns a todas as licenciaturas, o terceiro eixo está subdividido em Ciências da Natureza e Matemática e Ciências Agrárias, nos quais são abordados conteúdos específicos, e o quarto eixo tem como propósito a inserção dos discentes na comunidade. O curso tem duração de quatro anos e é desenvolvido em regime de alternância estruturado em dois tempos: tempo 
escola e tempo comunidade. O tempo escola é constituído pelas ações desenvolvidas no Campus São Lourenço do Sul/RS e contempla períodos de formação presencial. O tempo comunidade é desenvolvido nos locais de moradia e trabalho dos educandos e contempla períodos intensivos de formação presencial nas comunidades, no qual o educando realiza suas atividades e leituras de mundo a partir do seu contexto de atuação e vivências. O regime de alternância assume, no curso, a dimensão formativa da comunidade, enquanto espaços físicos, sociais e políticos.

Esses saberes contextuais, vistos como do mundo, são necessários, pois "o docente carrega consigo saberes disciplinares, curriculares e experienciais, mas acima de tudo sociais" (TARDIF, 2002, p. 34) e aproximam a compreensão dos estudantes. Os saberes curriculares e disciplinares também são importantes para a formação dos sujeitos que vivem no campo, mas as vivências e as experiências possibilitam distintas aprendizagens. Segundo o autor, os saberes campesinos se revelam na forma de gestos, danças e ações, que levam os sujeitos, muitas vezes não inseridos no mesmo território, a pensar e refletir sobre a sua cultura, sua luta pelo direito à educação, ao pedaço de terra e à melhor qualidade de vida para os seus filhos, sejam eles agricultores, pescadores, quilombolas, ou todos aqueles que fazem parte e se assumem como povos do campo.

Se não estamos inseridos nas problemáticas do campo, apenas observamos seus movimentos de lutas pelos direitos, e dificilmente compreendemos as dificuldades enfrentadas pelos campesinos. Portanto, para realizar a pesquisa optamos pela inserção no contexto, de forma a compreender profundamente as problemáticas vivenciadas, bem como entender algumas características do curso e poder analisar a proposta curricular, a partir do olhar dos discentes, sobre as práticas de ensino pensadas para o contexto do campo.

São muitos os questionamentos quando se opta por construir uma educação a partir dos movimentos sociais: 1) Que práticas de ensino podem ser pensadas a fim contextualizá-las ao campo? 2) Como o docente para 0 campo é constituído, isto é, que cursos e formações continuadas específicas para a Educação do Campo existem? e 3) Como os alunos percebem o ensino 
e a prática pedagógica dos professores do curso, relacionados ao seu contexto? Essas e outras inquietações sobre a Educação do Campo, bem como a contextualização dos saberes sobre as Ciências da Natureza e Ciências Agrárias, nos impulsionaram a sair da "zona de conforto" e a dialogar com os discentes do CLEC.

A presente análise centra-se na questão 3 apresentada acima, sob um viés cartográfico, buscando identificar os territórios existenciais habitados pelos discentes do curso e suas percepções sobre o CLEC, as práticas docentes e a integração com a comunidade do campo. Para isso, apresentamos os resultados dialogando com alguns autores que defendem a educação popular, com foco especial para o campo.

\section{CARTOGRAFIA DO CLEC: A VISÃO DISCENTE}

O CLEC busca formar docentes capazes de atrelar o conhecimento científico ao conhecimento de mundo, dito como prático/comum aos sujeitos que vivem e dependem do campo, saberes oriundos das experiências de vida, do fazer diário, para desse modo contribuir para uma maior produção do conhecimento a partir das experiências de vida de cada sujeito que compõem o território do campo. Assim, consideramos importante conhecer um pouco mais sobre esses discentes, sua identidade social, comunidade, expectativas para 0 curso e como visualizam e compreendem a proposta. Para tanto, organizamos entrevistas semiestruturadas com os acadêmicos (que fazem parte da primeira turma do CLEC), a fim de detectar suas compreensões sobre o fazer docente no contexto do campo e suas expectativas e impressões sobre o curso.

A entrevista foi norteada por cinco perguntas que contribuíram para a produção dos dados. Estiveram presentes oito dos quinze estudantes matriculados, e iremos traçar o perfil de cada discente por meio de suas falas. Dentre os alunos entrevistados, três moram em São Lourenço e os demais são moradores do campo de cidades próximas. Apenas duas alunas possuíam vínculo com o magistério antes de ingressar no CLEC, os outros alunos trabalham e vivem da agricultura. 
Estamos disponibilizando um recorte do estudo, por isso os sujeitos entrevistados serão identificados neste estudo pela letra maiúscula " $A$ " de "aluno", seguida do número correspondente na lista de alunos que foi organizada em ordem alfabética, conforme a notação An. Para a análise das entrevistas, utilizou-se um ensaio do método cartográfico, proposto por Kastrup et al. (2012) em que descreve, por meio de pistas cartográficas, a forma para acompanhar processos, evitando a representação predeterminada de um objeto. Nesse percurso, passamos a atuar como um aprendiz cartógrafo, ao acompanhar e analisar o que acreditamos ser importante ao fenômeno em estudo. No estudo cartográfico não existe objetivos definidos a priori, apenas intenções cartográficas, que neste estudo se referem às expectativas e compreensões dos estudantes sobre o CLEC.

Neste sentido, uma das maiores problemáticas do campo é o êxodo rural dos jovens que, por falta de oportunidade de formação profissional, abandonam o campo na busca de emprego e oportunidades nas cidades. Um curso para formação de professores pode colaborar para diminuir os índices de evasão mantendo os jovens no campo, como mostra o relato da Aluna $A_{11}$ ao afirmar que "Pretendo me formar e atuar como professora na educação básica e seguir estudando através de uma formação continuada".

O relato corrobora a ideia de Arroyo de busca pela formação superior, permanecendo, valorizando e mantendo vivas as matrizes e raízes culturais do campo (ARROYO, 2011) ao desejar atuar como professora de ciências na Educação Básica do Campo. Além disso, podemos perceber o discurso da professora engajada nesta prática ao manifestar seu desejo pela formação continuada, de acordo com as necessidades dos sujeitos.

Entretanto, nem todos os alunos do CLEC pretendem se tornar professores, alguns buscam aprimorar os seus conhecimentos nas áreas das Ciências Agrárias e da Natureza a fim de potencializar o trabalho no campo, como percebido na fala da aluna $\left(\mathrm{A}_{4}\right)$, que afirma "Gosto muito de viver no campo e o curso tem me oportunizado permanecer na minha comunidade e através dos conhecimentos adquiridos poderei levar para o campo".

Percebemos pela fala da aluna que sua expectativa é de levar para o campo os conhecimentos adquiridos ao longo do curso, isso nos remete aos 
saberes disciplinares presentes em cursos e universidades e que podem "integrar-se igualmente a prática docente através da formação inicial e continuada" (TARDIF, 2002, p.38).

Também, pode-se inferir, pela fala, que a aluna tem uma visão mecanicista do ensino, no sentido de apenas transmitir o conhecimento adquirido ao longo do curso. Esta lógica reprodutivista faz parte da perspectiva do modelo epistemológico empirista, no qual o conhecimento é resultado de um objeto. Porém, o curso propõe o rompimento deste modelo, estimulando a produção de novos conhecimentos a partir do contexto do campo. Não basta possuir apenas os saberes disciplinares e curriculares, é preciso desenvolver os saberes experienciais, pois "eles incorporam-se à experiência individual e coletiva sob a forma de habitus e de habilidades, de saber-fazer e de saber-se" (TARDIF, 2002, p. 39).

Os saberes experienciais fazem parte da vida desses sujeitos, já os disciplinares são percebidos pelos discentes apenas nas instituições de ensino, quando buscam uma formação que dê respostas para os fenômenos presentes no seu fazer diário, como a escassez de água no verão para a agricultura. Essa problematização permite a alunos e professores do CLEC trocar experiências, de forma a organizar os saberes disciplinares para que permitam um aprendizado com maior significância para os campesinos, bem como os demais grupos étnico-sociais representados no curso.

Assim, percebemos a necessidade de vincular as aprendizagens no tempo escola às experiências cotidianas dos discentes, bem como o ensino para o campo ao trabalho e à cultura dos povos do campo, pois "[...] não podemos supor que só se educa na escola. Escola sim, mas vinculada ao mundo do trabalho, da cultura, ao mundo da produção, vinculada pela luta pela terra" (ARROYO, 2011, p. 77). A importância desta alternância entre tempo escola e tempo comunidade se revela na fala da aluna A9: "O que oportunizou minha inserção no curso superior foi a alternância, pois o tempo comunidade contribui para a minha permanência na comunidade".

Nesse sentido, a pedagogia da alternância presente na estrutura curricular do CLEC oportuniza aos sujeitos a permanência em suas comunidades, pois busca integrar a escola com a família e a comunidade do 
educando, valorizando a troca de conhecimentos e o fortalecimento dos laços familiares por meio do regime de alternância. A proposta do Regime da Alternância permite que o acadêmico não deixe suas atividades agrícolas ou extrativistas, por vincular os períodos de Tempo Escola com a entressafra, e o Tempo Comunidade quando as suas famílias precisam de sua colaboração na colheita.

A Pedagogia da Alternância faz parte da Pedagogia do Movimento, adotada pelo Movimento dos Sem Terra (MST). Segundo Carldart (2011), esta é um conjunto de diferentes pedagogias, todas em movimento, isto é, de acordo com a situação educativa, específica e vivenciada pelos grupos que compõem o MST, a pedagogia escolhida pelos docentes deverá contemplar a história e o contexto social de cada sujeito. Além disso, oportuniza aos sujeitos do campo os atos de habitar e desenvolver novos territórios existenciais, de acordo com suas vivências e experiências dos grupos que compõem o movimento.

Esta ainda é referência a toda a educação básica e superior pensada para o campo, pois busca "não se filiar a uma determinada pedagogia préconcebida, isto é, não se ensina a partir de matrizes pedagógicas utilizadas pelas escolas da cidade, mas se destaca ao pensar em como a partir das pedagogias já existentes poderia reestruturá-la de acordo com o contexto do campo, por isso o MST coloca todas as pedagogias em movimento" (CALDART, 2011, p.98).

Neste processo contínuo de valorização dos territórios existenciais dos sujeitos que vivem e dependem do campo, foi perguntado para os estudantes sobre quais fatores contribuíram para a inserção no curso e quais as expectativas/ próximos caminhos a trilhar após a conclusão do curso, obtivemos novas informações pertinentes, dentre elas destaca-se:

A questão de sermos a primeira turma dificultou um pouco nossa inserção no curso, além de vivenciarmos a falta de professores. Dentre os próximos caminhos a partir da convivência e conversas com as pessoas do campo sentimos a necessidade de fazer a diferença entre os professores da cidade que lecionam no campo sem prazer (ALUNO As). 
Percebe-se que os alunos e professores tiveram que se adaptar a nova proposta curricular baseada na alternância, pois muitos docentes não se enquadravam no perfil de professor do campo, embora uma escola do campo precise de um currículo que contemple necessariamente a relação com o trabalho na terra (ARROYO, 2011, p. 57).

Sabendo que o CLEC tem o objetivo de articular as áreas do conhecimento a realidade dos discentes, o desafio docente está na adequação a essa realidade e o rompimento com o modelo de ensino predominante, mas podemos inferir, a partir dos extratos das entrevistas com os estudantes, que esta adaptação não é alcançada por muitos docentes. No nosso entendimento, isso ocorre porque pensar em metodologias que contemplem os conceitos articulados de forma multidisciplinar não é fácil, principalmente por esses docentes possuírem uma formação disciplinar, sem momentos de interlocução entre áreas durante sua formação. Ainda afirmamos, mesmo que sem um estudo mais longo e detalhado sobre o tema, que esta não adaptação contribui para que alguns docentes se afastem do curso, além de dificultar a reposição do quadro docente do curso.

Entretanto, aqueles docentes que permanecem têm vivenciado um novo momento de mudanças na educação, habitando assim novos territórios que não existiam previamente em seu domínio de ação. Ali são desafiados a formar sujeitos capazes de atuar em várias áreas do conhecimento, além de sujeitos que valorizam suas raízes, sua história de vida e, sejam autônomos ao lidar com a realidade do campo. Constata-se a carência de professores qualificados para atuar em cursos de licenciatura do campo, e isso os próprios alunos reconhecem, como podemos ver no fragmento da fala da aluna $(A 9)$ : "[...] sentimos a necessidade de fazer a diferença entre os professores da cidade que lecionam no campo sem prazer".

Esse sentimento se dá pelo fato dos discentes reconhecerem que muitos docentes olham apenas para as dificuldades enfrentadas no trabalho do campo sem visualizarem as alternativas de superação. No entanto, o desafio está em ver as situações diárias como possibilidades de fazer a diferença pensando em práticas pedagógicas de acordo com a comunidade local. Para tanto, os sujeitos e a comunidade precisam ser conhecidos, bem como os 
projetos que podem ser pensados a fim de abordar os conceitos articulados às práticas cotidianas dos estudantes.

Além disso, existe o movimento dos discentes, pela necessidade de fazer a diferença e de lutar contra a hegemonia predominante na educação básica do campo, que está relacionado à s experiências de trabalho, ligadas ao saber experiencial estruturados no início da carreira (TARDIF, 2002). Ao questionarmos quais os saberes são necessários para a formação do professor de Ciências que atuará na Educação do Campo, percebemos através dos diferentes relatos muitas concepções sobre os saberes necessários à formação docente e podem ser percebidas na fala da aluna $\left(A_{4}\right)$ :

\begin{abstract}
Acreditamos que a partir da vivência dos estudantes podemos aplicar os conceitos, mas para isso deve existir uma troca, no qual, professor e aluno compartilham as experiências. Além disso, o professor precisa valorizar os saberes dos discentes, aprender com o dia a dia deles adaptando o conteúdo, por exemplo: onde os estudantes veem as plantas? Os estudantes precisam ir para a mata e ver, tocar, sentir o cheiro e não estudar uma planta do nordeste ou estudar sobre poluição do nordeste, sendo que na nossa região também existe poluição (ALUNO $\mathrm{A}_{4}$ ).
\end{abstract}

A necessidade de conhecer e ouvir as experiências de vida dos estudantes, bem como estar inserido em um mesmo território existencial, seja ele espaço físico ou emocional, pode ser percebida nas falas quando sugerem: "[...] o professor precisa valorizar os saberes dos discentes, aprender com o dia a dia deles adaptando o conteúdo, para isso, se faz necessário colocar-se no lugar dos discentes, inserindo-se no mesmo espaço de convivência (MATURANA, 2005) a fim de significar os conteúdos abordados no espaço escolar.

Nesse sentido, percebe-se que as experiências iniciais sobre o que acontece no espaço de convivência dos discentes podem ser aproveitadas e articuladas a prática docente conforme enfatiza o aluno $\mathrm{A}_{9}$ : "É preciso introduzir um pouco de agroecologia nas escolas e conscientização do uso do agrotóxico. Também amar o campo, amar ser professor, independentemente do lugar, salário e dificuldades". 
A referida manifestação gerou muitas discussões e problematizações, contribuindo para que os discentes reflitam sobre o seu operar enquanto futuros docentes do e no campo. A necessidade de conhecer e ouvir as experiências de vida dos estudantes e de valorizar os saberes do campo, está expressa no final da fala "[...]) amar o campo, amar ser professor, independentemente do lugar, salário e dificuldades". Ela revela a importância de um sentimento de pertencimento ao fazer docente e uma compreensão sobre o papel da escola e comunidade, que gera "[...] emoções, afetos, capacidade não somente de pensar nos alunos, mas igualmente de perceber e de sentir suas emoções, seus temores, suas alegrias, seus próprios bloqueios afetivos" (TARDIF, 2002, p.130).

Nesse sentido, os docentes do CLEC propõem práticas de trabalho no coletivo a fim de aceitar as diferenças entre os sujeitos do campo. Além disso, só a teoria, desvinculada da prática, não dá conta da aprendizagem; é preciso, como destaca a aluna $A_{4}$, ao se referir a pedagogia voltada ao campo: "[...] ir para a mata e ver, tocar, sentir o cheiro e não estudar uma planta do nordeste ou estudar sobre poluição do nordeste, sendo que na nossa região também existe poluição".

Isso nos leva a refletir sobre os diferentes territórios de habitação nos quais determinados conceitos vistos na escola podem ser contextualizados ao campo, pois se faz necessário expandir/emancipar o ensino, não se aprende apenas na escola, mas nos diferentes espaços, inclusive na mata nativa e no trabalho com a agricultura.

Além disso, o ensino laboratorial exige um espaço com todos os recursos necessários para a experimentação e produção de novos conhecimentos, pois a utilização da experimentação de acordo com Rosito (2008) é considerada essencial para a aprendizagem científica. No entanto, o laboratório de ciências precisa ser o próprio campo, isto é, precisamos sair das quatro paredes, romper com o modelo de ensino predominante, pois para compreendermos uma teoria se faz necessário experimentá-la, conforme menciona Freire (1997). Como revela a fala da aluna $A_{4}$, "uma troca, na qual professor e aluno compartilham as experiências". Neste mesmo sentido, o ensino não pode ser descontextualizado, pois se assim o for, que prazer o 
aluno terá em estar na escola na qual só se ensina sobre plantas e animais que não fazem parte da sua região?

É necessário refletir sobre que educação do campo é desejada: uma educação que forme sujeitos capazes de atuar em várias áreas do conhecimento, que reflita e articule os conceitos vistos na escola com o seu contexto. Ao serem questionados sobre a proposta pedagógica do CLEC, baseada no regime de alternância, de que forma tem influenciado no fazer discente e a respeito das facilidades e dificuldades no curso com essa asserção, obtivemos várias compreensões, mas vamos destacar a fala da aluna A9: "A vantagem está em poder ter um tempo para a família e outro para o estudo, mas as disciplinas encaminham muitas atividades para serem desenvolvidas no tempo comunidade".

O regime de alternância, descrito nas discussões oportuniza a ação discente nos seus diferentes espaços, pois ela "tem o trabalho produtivo como princípio de uma formação humanista que articula dialeticamente ensino formal e trabalho produtivo" (RIBEIRO, 2009, p.31). No entanto, a compreensão dos alunos sinaliza para o excesso de atividade proposta pelos docentes, e este é um fator que merece ser repensado. A fala da aluna também remete para a carga horária das aulas uma vez que há aulas nos dois turnos ficando "muitas atividades para serem desenvolvidas no tempo comunidade". A fala sinaliza a necessidade de um tempo maior para o cumprimento das atividades, uma vez que no tempo comunidade, além de trabalharem no campo, através de um trabalho muitas vezes pesado e cansativo, também precisam desenvolver outras atividades vinculadas à disciplina Práticas Educativas e Comunitárias ${ }^{1}$.

Entre os objetivos do CLEC está oportunizar processos de formação dos sujeitos e esses processos devem estar interligados às formas identitárias dos povos do campo, já que ao planejar suas aulas, o docente precisa conhecer quem são os seus estudantes, quais suas histórias de vida, culturas, entre outros aspectos que influenciam e podem contribuir para uma melhor

\footnotetext{
${ }^{1}$ Esta disciplina é ofertada em dois momentos (3ำ e $4^{\circ}$ semestres) do CLEC, em regime de alternância: Tempo Comunidade, no qual objetiva através de estudos experimentais e observacionais, articular a linguagem matemática na resolução de problemas relacionados aos fenômenos científicos e a educação no/do campo; e o Tempo Escola, onde estes dados coletados são analisados e explorados.
} 
aprendizagem neste contexto, ou seja, os territórios de habitação dos discentes precisam ser valorizados ao planejar uma prática de ensino no contexto do campo. Neste sentido, mencionamos os "tempos e espaços de aprendizagem" (CALDART, 2011) como ações flexíveis, de acordo com o proposto pelo CLEC ao oportunizar a permanência do aluno tanto na instituição de ensino como na sua comunidade.

Entretanto, a concepção de educação do campo precisa estar atrelada ao contexto social dos discentes, as lutas por um pedaço de terra, a luta pelo acesso à educação, a valorização da sua cultura, identidade, saberes, modos de produção e seu ecossistema que precisa ser preservado.

\footnotetext{
É neste contexto que esta organização curricular foi pensada, por áreas do conhecimento, que tem neste curso como desafio principal a habilitação para a docência por área, mas também a organização do estudo para além das aulas, e as aulas para além de um ensino apenas transmissivo, mas que não descuide da apropriação do conhecimento historicamente produzido pela humanidade e que ajudem a compreensão da realidade que precisamos transformar. (CALDART, 2011. p.105).
}

Nesse sentido, o curso tem buscado a partir da proposta curricular baseada no regime de alternância, valorizar o contexto sociocultural dos discentes, mas para isso os componentes curriculares devem estar de acordo com a realidade dos sujeitos, ou seja, as propostas pedagógicas precisam contemplar a necessidade de cada comunidade, por isso o currículo tem o papel de direcionar os processos educativos escolares e de mostrar como esses processos devem ser feitos.

A estrutura curricular baseada no regime de alternância tem oportunizado ao aluno um tempo para o desenvolvimento de práticas de pesquisa social e educacional, ou seja, o aluno tem um tempo que pode variar de uma a duas semanas para investigar, conhecer as escolas do campo e a comunidade no qual se situa e também um tempo para o aprofundamento teórico sobre as áreas do conhecimento atreladas ao contexto do campo. Neste sentido, os currículos se constituem de percursos a serem seguidos, dos saberes a serem construídos, das práticas e atividades a serem experiências, 
das relações sociais a serem vividas, da cultura a ser cultivada e dos valores a serem exercitados (CALDART, 2002).

Para isso, se faz necessário que o futuro educador do campo compreenda e articule as áreas do conhecimento ao seu fazer diário a partir de um currículo direcionado para os diferentes territórios de habitação dos educandos, pois não podemos desvincular a teoria da prática. Além disso, as compreensões iniciais sobre o curso bem como as expectativas frente à ação docente devem estar primeiramente presentes no pensar dos futuros docentes para que assim, possam de forma crítica e reflexiva problematizá-las nos diferentes espaços educativos.

\section{CONSIDERAÇÕES FINAIS}

Falar sobre o CLEC direcionando nosso olhar para a formação docente proporcionou discussões sobre o operar docente no contexto do campo. Pelas falas dos discentes, observou-se a importância da formação inicial para uma melhor atuação nas escolas de educação básica, assinalando para a interação entre o conteúdo científico e as vivências experienciais na prática pedagógica dos docentes que atuam e que buscam constituir novos territórios existenciais a partir de seus espaços de atuação.

Os discentes salientaram a necessidade de desenvolverem práticas pedagógicas direcionadas para o contexto dos estudantes, respeitando os períodos de alternâncias e também a necessidade de uma formação continuada aos docentes, para que o seu fazer pedagógico se aproxime da sua realidade. O CLEC, por estar estruturado em regime de alternância, oportuniza que os sujeitos sejam inseridos nos diferentes espaços de aprendizagem, sejam na escola, na universidade ou no seu contexto familiar, pois a educação do campo está permeada por sujeitos que vivem, dependem e aprendem no campo e essas vivências e concepções podem ser (re)pensadas pelo CLEC a fim de oportunizar que os discentes se tornem professores do campo imbuídos em práticas cotidianas pedagógicas articuladas às áreas do conhecimento de Ciências da Natureza e Ciências Agrárias, ênfase do curso, apesar de não diretamente tratadas ao longo desta análise. 
Nesse sentido, destaca-se, das falas, a existência de expectativas e compreensões dos discentes sobre o curso, a respeito da sua formação, o que possibilita aos professores e alunos que atuam no curso uma preparação para atuar sabendo das situações adversas e complexas advindas da prática pedagógica para o campo. O regime de alternância busca ensinar de acordo com as vivências dos sujeitos articulando às áreas do conhecimento, o que exigirá capacidades e habilidades como estratégias pensadas para fazer e aprender no campo.

\section{REFERÊNCIAS}

ALVAREZ, Johnny; PASSOS, Eduardo. Cartografia é habitar um território existencial. In: PASSOS, Eduardo; KASTRUP, Virgínia; ESCÓSSIA, Liliana da. Pistas do método da cartografia: Pesquisa-intervenção e produção de subjetividade. Porto Alegre: Sulina, 2012.

ARROYO, Miguel Gonzales; CALDART, Roseli Salete; MOLINA, Mônica Castagna. Por uma educação do campo. 5. ed. Petrópolis, RJ: Vozes, 2011.

ARROYO, Miguel Gonzales; FERNANDES, Bernardo Mançano. A educação básica e o movimento social do campo. Coleção Por uma Educação Básica do Campo, vol. 2. Brasília, DF: Articulação Nacional Por uma Educação Básica do Campo, 1999.

BIANCHETTI, Lucídio; JANTSCH, Ari Paulo. Interdisciplinaridade para além da filosofia do sujeito. Rio de Janeiro: Editora Vozes, 2011.

BOGDAN, Robert; BIKLEN, Sari. Investigação qualitativa em educação: uma introdução à teoria e aos métodos. Porto: Porto Ed. 1994.

CALDART, Roseli Salete. Licenciatura em Educação do Campo e projeto formativo: Qual o lugar da docência por área? In: CALDART, Roseli. (Org.). Caminhos para transformação da escola: Reflexões desde práticas da Licenciatura em Educação do Campo. São Paulo: Expressão Popular, 2011.

CALDART, Roseli Salete. Ser educador do povo do campo. In: KOLLING, Edgard Jorge; CERIOLI, Paulo Ricardo; CALDART, Roseli Salete. (Org.). Educação do campo: Identidade e políticas públicas. Brasília, 2002.

DELEUZE, Gilles; GUATTARI, Félix. Mil Platôs: Capitalismo e Esquizofrenia. Vol. 1. Rio de Janeiro: Editora 34, 1995.

FREIRE, Paulo. Pedagogia da Autonomia. Rio de Janeiro: Paz e Terra, 1997. 
FREIRE, Paulo. Pedagogia do oprimido, 17a ed Rio de Janeiro, Paz e Terra, 1987.

FURG. Universidade Federal do Rio Grande. Curso de Licenciatura em Educação do Campo: Ênfase em Ciências da Natureza e Ciências Agrárias Rio Grande/RS. In: Projeto Pedagógico do curso de Licenciatura em Educação do Campo: Ênfase em Ciências da Natureza e Ciências Agrárias/FURG. 2013.

JAPIASSU, Hilton. Interdisciplinaridade e Patologia do saber. Rio de Janeiro: Editora Imago, 1976.

KASTRUP, Virgínia, et. al. (Org.). Pistas do método da cartografia: Pesquisa intervenção e produção de subjetividade. Porto Alegre: Sulina, 2012.

MATURANA, Humberto. Emoções e linguagem na educação e na política. Belo Horizonte: Ed. UFMG. 2005.

ROSITO, João. O Ensino de Ciências e a Experimentação. In: MORAES, Roque. (Org.). Construtivismo e Ensino de Ciências: Reflexões Epistemológicas e Metodológicas. Porto Alegre: EDIPUCRS, 2008.

RIBEIRO, Marlene. Trabalho-educação no Movimento Operário e no Movimento Camponês: unidade na diversidade. In: CANÁRIO, Rui; RUMMERT, Sonia Maria. Mundos do Trabalho e Aprendizagem. Lisboa: Educa, 2009. p. 119-132.

ROSA, Daniela Souza de, CAETANO, Maria Raquel. Da educação rural à educação do campo: uma trajetória... Seus desafios e suas perspectivas. Colóquio: Revista Científica da FACCAT, v. 6, n. 1-2, p. 21-34. 2008.

TARDIF, Maurice. Saberes docentes e formação profissional. Petrópolis, RJ: Vozes, 2002.

Recebido em: 08/04/2018

Aprovado em: 14/07/2018 